Journal Club

Editor's Note: These short reviews of recent JNeurosci articles, written exclusively by students or postdoctoral fellows, summarize the important findings of the paper and provide additional insight and commentary. If the authors of the highlighted article have written a response to the Journal Club, the response can be found by viewing the Journal Club at www.jneurosci.org. For more information on the format, review process, and purpose of Journal Club articles, please see http://jneurosci.org/content/ preparing-manuscript\#journalclub.

\title{
Valproic Acid for a Treatment of Retinitis Pigmentosa: Reasons for Optimism and Caution
}

\author{
Levi Todd ${ }^{1}$ and Christopher Zelinka ${ }^{2}$ \\ ${ }^{1}$ Department of Neuroscience, College of Medicine, Ohio State University, Columbus, Ohio 43210, and 2Department of Biological Science, Florida State \\ University, Tallahassee, Florida 32306 \\ Review of Vent-Schmidt et al.
}

Retinitis pigmentosa (RP) is a family of heritable retinopathies characterized by a progressive loss of rod photoreceptors that eventually leads to blindness. Hundreds of individual mutations found in $>60$ genes are known to result in RP, with varying severity and modes of inheritance (Manes et al., 2015). The heterogeneous nature of this disease suggests that diverse molecular mechanisms are responsible for degeneration, making it difficult to find umbrella therapies. There is currently no cure for any form of RP, and treatment options are limited. Current options include oral supplementation of vitamin A, $\omega$-3 fatty acids, or lutein, which have modest or unclear benefits (for review, see Rayapudi et al., 2013), or expensive and invasive prosthetic implants (Chuang et al., 2014). Cooperation between animal and clinical research is paramount in finding realistic strategies to fight $\mathrm{RP}$, given its complex and devastating nature.

Valproic acid (VPA) has emerged as a potential treatment for RP, and a Phase II clinical trial has recently been completed (NCT01233609). This trial was motivated by a preliminary study reporting that oral

Received March 21, 2017; revised April 20, 2017; accepted April 21, 2017. The authors declare no competing financial interests.

Correspondence should be addressed to Levi Todd, Department of Neuroscience, College of Medicine, Ohio State University, 4190 Graves Hall, 333 West 10th Avenue, Columbus, OH 43210. E-mail: Todd.136@osu.edu.

DOI:10.1523/JNEUROSCI.0774-17.2017

Copyright $\odot 2017$ the authors $\quad 0270-6474 / 17 / 375215-03 \$ 15.00 / 0$
VPA improved visual acuity in 9 of 13 eyes from RP patients (Clemson et al., 2011). However, this initial report garnered significant criticism regarding lack of control groups, improper statistical analysis, and failure to account for VPA-induced side effects (Sandberg et al., 2011). Inspired by Clemson et al. (2011) and the potential benefit VPA may offer to people suffering from RP, 3 additional patients were offered VPA on a "compassionate basis" (Sisk, 2012). In that study, all 3 patients were removed prematurely from VPA treatment due to a reduction in visual acuity and harmful side effects (Sisk, 2012). The authors hypothesized that genotype differences may explain the detrimental effects of VPA on this cohort of patients and that VPA may only benefit patients with autosomal dominant RP (adRP) (Sisk, 2012).

In a recent report in The Journal of Neuroscience, Vent-Schmidt et al. (2017) investigated the efficacy of VPA across different mutant animal models of adRP. The authors took advantage of established Xenopus laevis lines expressing different adRP-linked alleles of human $R H O$, which encodes rhodopsin, the visual pigment in rod photoreceptors (Tam and Moritz, 2006, 2009; Tam et al., 2014). Mutations in $\mathrm{RHO}$ are among the most prevalent causes of RP, accounting for nearly onethird of adRP (Daiger et al., 2013), and they are categorized into as many as six classes based on suspected underlying pathological mechanisms (Mendes et al., 2005). Class I and II RHO mutations are generally classified based on protein folding and localization properties. Class I mutants, such as Q344ter, fold and bind chromophore normally but are mislocalized across the photoreceptor plasma membrane. Class II mutants, represented by T17M and P23H, exhibit improper folding and binding to chromophore, and retention in the ER/Golgi. T4K, a Class IV mutant, shows reduced protein stability, albeit without obvious misfolding. The authors applied VPA to transgenic frogs expressing normal or Class I (Q344ter), Class II (T17M, P23H), or Class IV (T4K) mutant human $\mathrm{RHO}$ alleles. Similar to the original report in humans, the authors found that VPA was neuroprotective and improved visual function in RP frogs expressing the $\mathrm{P} 23 \mathrm{H}$ mutant $\mathrm{RHO}$. However, VPA was either ineffective or deleterious to the photoreceptors in the three other genotypes tested. Together, these data suggest that VPA can be beneficial or harmful to diseased rods depending on the underlying genetic mutation. This result was foreshadowed in the published human data and may explain the difficulty observed in clinical studies using VPA to treat all forms of RP. Similarly, in mouse models of RP, VPA was found to be either protective or toxic to photoreceptors depending on the mouse strain (Mitton et al., 2014). 
Despite these conflicting results, $\mathrm{P} 23 \mathrm{H}$ mutations cause the largest portion of RP cases in North America, and understanding the mechanisms underlying the protective effects of VPA may suggest promising new treatments for those afflicted with this class of mutation. VPA can exert its effects through a wide variety of mechanisms, such as indirectly enhancing GABA signaling, influencing cell signaling through PKC, PI3K, and glycogen synthase kinase, reducing ER stress, and inhibiting histone deacetylases (HDACs) (for review, see Chuang et al., 2009; Schloesser et al., 2012). To better understand how VPA protects $\mathrm{P} 23 \mathrm{H}$ mutant photoreceptors, Vent-Schmidt et al. (2017) tested nine compounds with pharmacological properties similar to VPA. They found that HDAC inhibitors, and no other class of compounds, recapitulated the VPA-induced neuroprotective effects on photoreceptor survival in the $\mathrm{P} 23 \mathrm{H}$ mutant, whereas the HDAC inhibitors exacerbated photoreceptor degeneration in $\mathrm{T} 4 \mathrm{~K}, \mathrm{~T} 17 \mathrm{M}$, and Q344ter mutants. This argues that VPA affects photoreceptor survival by acting as an HDAC inhibitor and that inhibition of HDACs may underlie both the protective and detrimental effects of VPA depending on the genetic background.

HDAC inhibitors influence chromatin structure and function by maintaining an "open" conformation, allowing transcription factors access to the genome, and hence allowing transcription. VPA directly inhibits HDAC1 and causes hyperacetylation of histones (Phiel et al., 2001). HDAC inhibitors have shown therapeutic potential in animal models of neurodegenerative diseases, such as Huntington's, Parkinson's, Alzheimer's, amyotrophic lateral sclerosis, and spinal muscular atrophy, and their beneficial effects have been linked to their ability to increase the expression of neurotrophic factors and promote an anti-inflammatory environment (Chuang et al., 2009). In addition, VPA has been shown to promote retinal ganglion cell survival after optic nerve crush, potentially through elevation of neurotrophic factors (Zhang et al., 2012). VPA has also been reported to increase levels of neurotrophic factors BDNF and GDNF in wildtype mouse retinas (Mitton et al., 2014). However, HDAC inhibitors also have undesirable actions. For example, VPA has been reported to cause intolerable side effects in patients (Sisk, 2012) and photoreceptor toxicity in mice (Mitton et al., 2014). Trichostatin-A, another HDAC inhibitor, suppressed transcription in photoreceptors and caused cell death in developing retinal explants (Chen and Cepko, 2007). Therefore, more studies are needed to further assess the specific gene expression changes necessary for both beneficial and detrimental effects of VPA.

HDAC inhibitors are also known to induce autophagy (Robert et al., 2011), a response that has been demonstrated to protect stressed photoreceptors (Zhou et al., 2015). Given its position in rhodopsin (Palczewski et al., 2000) and reduced binding to 11-cis-retinal chromophore (Anukanth and Khorana, 1994), P23H rhodopsin is suspected of misfolding, accumulating in the rod inner segments, and triggering the ER stress response (Tam and Moritz, 2006). Vent-Schmidt et al. (2017) therefore examined whether autophagy may be a downstream mechanism through which VPA protects photoreceptors. Using an antibody with specificity for human rhodopsin, the authors observed that treatment with VPA nearly abolished detection of human $\mathrm{P} 23 \mathrm{H}$ rhodopsin while leaving wild-type frog rhodopsin intact. At the same time, as observed by electron microscopy, VPA induced the appearance of autophagic structures in the rod inner segments of both normal and $\mathrm{P} 23 \mathrm{H} \mathrm{mu-}$ tant retinas. Together, this evidence supports the hypothesis that $\mathrm{P} 23 \mathrm{H}$ rhodopsin accumulates and initiates a cellular stress response, and that VPA acts to clear mutant rhodopsin via autophagy.

One potential drawback to the studies presented by Vent-Schmidt et al. (2017) is the use of animal models with variable transgenic expression levels. For example, the authors found no effect of VPA on a transgenic line of $\mathrm{T} 17 \mathrm{M}$ frogs in which T17M accounted for $27 \%$ of total rhodopsin expressed. However, VPA had significant effects on a similar transgenic line in which T17M protein accounted for $5 \%$ of total rhodopsin. The authors interpreted this as a "floor effect," whereby the expression levels in the former transgenic line resulted in cellular damage beyond that which VPA treatment could increase. In the T17M line with lower RHO expression levels, increased photoreceptor death was observed because levels of cellular damage could be exacerbated by VPA treatment. With the revolution of gene editing tools, it may be possible and advantageous to generate precise, knock-in mutant models of human RP to better represent native expression levels, especially for adRP. Furthermore, from the clinical end, it would be desirable to develop methods to measure relative expression levels across RP genotypes.
In conclusion, Vent-Schmidt et al. (2017) found that VPA, potentially acting through HDAC inhibition and autophagy, can promote the clearance of misfolded $\mathrm{P} 23 \mathrm{H}$ rhodopsin, slow rates of photoreceptor death, and preserve visual activity. These data support VPA or inhibition of HDACs in general, as a potential treatment for some forms of RP. However, the authors found that VPA treatment was not beneficial across genotypes and accelerated degeneration caused by some $\mathrm{RHO}$ mutations. This article thus provides a cellular and genetic context that may explain when VPA is appropriate to use and when it should be avoided. Although the results of the current clinical trial testing VPA for a treatment of RP have yet to be published, the data presented by VentSchmidt et al. (2017), taken along with negative clinical reports (Sisk, 2012), urge extreme caution when using VPA to treat RP.

\section{References}

Anukanth A, Khorana HG (1994) Structure and function in rhodopsin: requirements of a specific structure for the intradiscal domain. J Biol Chem 269:19738-19744. Medline

Chen B, Cepko CL (2007) Requirement for histone deacetylase activity for the expression of critical photoreceptor genes. BMC Dev Biol 7:78. CrossRef Medline

Chuang AT, Margo CE, Greenberg PB (2014) Retinal implants: a systematic review. $\mathrm{Br} J$ Ophthalmol 98:852-856. CrossRef Medline

Chuang DM, Leng Y, Marinova Z, Kim HJ, Chiu CT (2009) Multiple roles of HDAC inhibition in neurodegenerative conditions. Trends Neurosci 32:591-601. CrossRef Medline

Clemson CM, Tzekov R, Krebs M, Checchi JM, Bigelow C, Kaushal S (2011) Therapeutic potential of valproic acid for retinitis pigmentosa. Br J Ophthalmol 95:89-93. CrossRef Medline

Daiger SP, Sullivan LS, Bowne SJ (2013) Genes and mutations causing retinitis pigmentosa. Clin Genet 84:132-141. CrossRef Medline

Manes G, Guillaumie T, Vos WL, Devos A, Audo I, Zeitz C, Marquette V, Zanlonghi X, Defoort-Dhellemmes S, Puech B, Said SM, Sahel JA, Odent S, Dollfus H, Kaplan J, Dufier JL, Le Meur G, Weber M, Faivre L, Cohen FB (2015) High prevalence of PRPH2 in autosomal dominant retinitis pigmentosa in France and characterization of biochemical and clinical features. Am J Ophthalmol 159:302-314. CrossRef Medline

Mendes HF, van der Spuy J, Chapple JP, Cheetham ME (2005) Mechanisms of cell death in rhodopsin retinitis pigmentosa: implications for therapy. Trends Mol Med 11: 177-185. CrossRef Medline

Mitton KP, Guzman AE, Deshpande M, Byrd D, DeLooff C, Mkoyan K, Zlojutro P, Wallace A, Metcalf B, Laux K, Sotzen J, Tran T (2014) Different effects of valproic acid on photoreceptor loss in Rd1 and Rd10 retinal degeneration mice. Mol Vis 20:1527-1544. Medline 
Palczewski K, Kumasaka T, Hori T, Behnke CA, Motoshima H, Fox BA, Le Trong I, Teller DC, Okada T, Stenkamp RE, Yamamoto M, Miyano M (2000) Crystal structure of rhodopsin: a $G$ protein-coupled receptor. Science 289:739-745. CrossRef Medline

Phiel CJ, Zhang F, Huang EY, Guenther MG, Lazar MA, Klein PS (2001) Histone deacetylase is a direct target of valproic acid, a potent anticonvulsant, mood stabilizer, and teratogen. J Biol Chem 276:36734-36741. CrossRef Medline

Rayapudi S, Schwartz SG, Wang X, Chavis P (2013) Vitamin A and fish oils for retinitis pigmentosa. Cochrane Database Syst Rev 12: CD008428. CrossRef Medline

Robert T, Vanoli F, Chiolo I, Shubassi G, Bernstein KA, Rothstein R, Botrugno OA, Parazzoli D, Oldani A, Minucci S, Foiani M (2011) HDACs link the DNA damage response, processing of double-stranded breaks and autophagy. Nature 471:74-79. CrossRef Medline Sandberg MA, Rosner B, Weigel-DiFranco C,
Berson EL (2011) Lack of scientific rationale for use of valproic acid for retinitis pigmentosa. Br J Ophthalmol 95:744. CrossRef Medline

Schloesser RJ, Martinowich K, Manji HK (2012) Mood-stabilizing drugs: mechanisms of action. Trends Neurosci 35:36-46. CrossRef Medline

Sisk RA (2012) Valproic acid treatment may be harmful in non-dominant forms of retinitis pigmentosa. Br J Ophthalmol 96:1154-1155. CrossRef Medline

Tam BM, Moritz OL (2006) Characterization of rhodopsin $\mathrm{P} 23 \mathrm{H}$-induced retinal degeneration in a Xenopus laevis model of retinitis pigmentosa. Invest Ophthalmol Vis Sci 47: 3234-3241. CrossRef Medline

Tam BM, Moritz OL (2009) The role of rhodopsin glycosylation in protein folding, trafficking, and light-sensitive retinal degeneration. J Neurosci 29:15145-15154. CrossRef Medline

Tam BM, Noorwez SM, Kaushal S, Kono M, Moritz OL (2014) Photoactivation-induced instability of rhodopsin mutants $\mathrm{T} 4 \mathrm{~K}$ and $\mathrm{T} 17 \mathrm{M}$ in rod outer segments underlies retinal degeneration in $X$. laevis transgenic models of retinitis pigmentosa. J Neurosci 34:1333613348. CrossRef Medline

Vent-Schmidt R, Wen YJ, Zong RH, Chiu Z, Tam CN, May BM, Moritz OL (2017) Opposing effects of valproic acid treatment mediated by histone deacetylase inhibitor activity in four transgenic $X$. laevis models of retinitis pigmentosa. J Neurosci 37:1039-1054. CrossRef

Zhang ZZ, Gong YY, Shi YH, Zhang W, Qin XH, Wu XW (2012) Valproate promotes survival of retinal ganglion cells in a rat model of optic nerve crush. Neuroscience 224:282-293. CrossRef Medline

Zhou Z, Doggett TA, Sene A, Apte RS, Ferguson TA (2015) Autophagy supports survival and phototransduction protein levels in rod photoreceptors. Cell Death Diff 22:488-498. CrossRef Medline 